\title{
Radiation induced crosslinking effect on semi- interpenetrating polymer networks of poly(vinyl alcohol)
}

\author{
S. Mishra1, R. Bajpai ${ }^{1}$, R. Katare ${ }^{2}$, A. K. Bajpai ${ }^{*}$ \\ ${ }^{1}$ Department of Postgraduate Studies and Research in Physics, Rani Durgavati University, Jabalpur, 482001 (M.P.), India \\ ${ }^{2}$ Department of Physics, Government Autonomous Science College, Jabalpur, 482001 (M.P.), India \\ ${ }^{3}$ Bose Memorial Research Laboratory, Department of Chemistry, Government Autonomous Science College, Jabalpur, \\ 482001 (M.P.), India
}

Received 21 March 2007; accepted in revised form 23 May 2007

\begin{abstract}
Semi-IPNs with varying contents of poly(vinyl alcohol) (PVA), poly acrylamide (PAM) and crosslinker N,N'methylene bis acrylamide (MBA) were prepared by redox polymerization method. The structural and morphological properties were studied by Fourier transform infrared (FTIR) spectroscopy, environmental scanning electron microscopy (ESEM) and X-ray diffraction (XRD) methods, respectively. It was found that the surface of the hydrogel is heterogeneous with separated domains. XRD result shows the semi-crystalline nature of the semi-IPNs. The prepared semi-IPNs of different compositions were subjected to gamma irradiation ( 2 to $250 \mathrm{kGy})$ and the radiation induced effects on their strength of the semi-IPNs were studied by measuring the surface microhardness using a Vickers microhardness tester. Significant changes were observed in the Vickers microhardness, which were correlated with molecular architecture of the prepared semi-IPNs.
\end{abstract}

Keywords: mechanical properties, polymer gels, biocompatible polymers, irradiation

\section{Introduction}

Hydrogels have gained popularity as scaffolds for tissue engineering due to their high water content, good biocompatibility, and consistency similar to soft tissue [1]. An effective role to develop mechanically strong polymeric materials has been through the preparation of interpenetrating polymer networks (IPNs) [2], which are defined as a combination of two polymers, in network form, of which at least one is synthesized and/or crosslinked in the immediate presence of the other without any covalent bonds between them. If one of the components of these IPNs has a linear structure instead of network structure it is called semi-IPN. IPNs have the following two characteristics: firstly, the polymers must be synthesized, or crosslinked, in the presence of the other; secondly, the combination must pro- vide the possibility of effectively producing advanced multicomponent, polymeric systems having new property profiles [3].

Radiation processing using $\gamma$-rays, electron beam or $\mathrm{X}$-rays has been demonstrated on a large commercial scale to be a very effective means of improving end use properties of various polymers [4]. It is a well-established and economical method of precisely modifying the properties of bulk polymer resins and formed polymer components [5]. When the radiation from source interacts with a polymer material, the polymer material absorbs its energy and active species such as radicals are produced, thereby, initiating various chemical reactions. There are three fundamental processes that are the results of these reactions. The different responses to radiation for different polymers are intrinsically

*Corresponding author, e-mail: akbmrl@yahoo.co.in

(C) BME-PT and GTE 
related to the chemical structures of the polymers. Crosslinking and degradation are two competing processes that always co-exist under radiation. The overall effect depends on which of the two is predominant at a certain time. Crosslinking is the most important effect of polymer irradiation and has the large number of applications because it can usually improve the mechanical and thermal properties and environmental and radiation stabilities for both preformed parts and bulk materials $[6,7]$. The effect of gamma irradiation on the surface microhardness of polyblends has been studied to detect radiationinduced crosslinking [8]. Besides the radiation crosslinking of hydrogels and orthopedic devices, radiation processing can have other applications in the biomaterials area [9].

Poly(vinyl alcohol) (PVA) is a well-known synthetic polymeric material. The biocompatibility of which justifies its inclusion in the class of biomacromolecules [10]. PVA is highly hydrophilic, non-toxic and biocompatible polymer with excellent film forming property. PVA films have high mechanical strength and long-term temperature stability [11]. These properties of PVA have to led their use in several biomedical and industrial applications including contact lenses [12], ophthalmic materials [13], tendon repair [14], as sorbents for dye wastes [15, 16], as sensors [17] and drug delivery system [18]. Some chemical hydrogels based on PVA are well known in literature [19]. PVA membranes have been chemically crosslinked with difunctional gluteraldehyde but leaching of harmful residues can limit its use in medical or pharmaceutical applications, therefore, other methods of chemical crosslinking of PVA have been investigated which includes the use of electron beam or gamma irradiation [20].

The use of poly(acrylamide) hydrogels in the field of agriculture [21] and biomedical [22] has been reported. Workers have synthesized polyacrylamide and gels derived from it using $\gamma$-irradiation [23]. For instance, Nizam El-Din and coworkers [24] have recently reported the use of gamma radiation in synthesis of hydrogel made up of PVA and polyacrylamide. However, the macromolecular structures arising from crosslinked polyacrylamide often suffer from poor mechanical properties, which put a limit over its applications where both hydrophilicity and mechanical strength are required. Thus, the combination of a preformed polymer such as PVA showing good mechanical performance with a hydrophilic polymer like polyacrylamide could prove to be a potential strategy for designing mechanically strong but hydrophilic networks. Moreover, as mentioned above the use of high-energy radiation may additionally support the development of mechanically strong polymers. Thus, being inspired by the challenges coming across in formulating a hydrophilic but mechanically sound polymer matrix, the authors planned to extend their earlier work $[25,26]$ on microhardness of measurements of semi IPN of PVA and crosslinked polyacrylamide (PAM). The use of gamma radiation may result in an enhance number of crosslinks within the polymer matrix which, in turn, will bring about a change in the overall performance of the end polymer. As PVA will not be crosslinked chemically, the exposure of the material to the radiation is likely to provide dimensional stability to the network.

The structural and morphological features obtained for un-irradiated specimens of semi-IPNs using Fourier Transform Infrared Spectroscopy (FTIR), Environmental Scanning Electron Microscopy (ESEM) and X Ray Diffraction (XRD) helps in understanding the overall effect of irradiation on the microhardness. The Vickers microhardness testing method is found to be versatile in revealing the structural, morphological and plasticization aspects in polymers [27].

\section{Experimental}

\subsection{Materials}

Poly(vinyl alcohol) (PVA) (98\% acetalized, molecular weight $14000 \mathrm{Da}$ ) was obtained from Research Lab Chem Industries, Mumbai, India and used without further purification. Polyacrylamide (Mol. wt. over $10^{6} \mathrm{Da}$ ) for FTIR spectral analysis was purchased from BDH (Poole, England) and used without any treatment. Acrylamide (AM) (Research Lab, Pune, India) was crystallized twice in methanol and dried in vacuum over anhydrous silica for a week. N,N'-methylene bis acrylamide (MBA) (Research Lab, Mumbai, India) was used as a crosslinking agent, potassium persulphate (KPS) (Loba Chemie Pvt. Ltd., Delhi, India) as an initiator and potassium metabisulphite (MBS) (Qualigens Fine Chemicals, Mumbai, India) as activator, respectively. Bidistilled water was used throughout the experiments. 


\subsection{Synthesis of IPN}

Semi-IPNs were prepared by redox polymerization method as reported elsewhere [28]. In a typical experiment, into $25 \mathrm{ml}$ of distilled water were added calculated amounts of PVA $(49.8 \%(\mathrm{w} / \mathrm{w}))$, acrylamide $(49.8 \%(\mathrm{w} / \mathrm{w}))$, MBA $(0.4 \%(\mathrm{w} / \mathrm{w}))$ and $1 \mathrm{ml}$ each of potassium metasulphite $(0.01 \mathrm{M})$ and potassium persulphate $(0.001 \mathrm{M})$. The PVA and acrylamide were dissolved in bidistilled water using magnetic stirrer to get homogeneous reaction. The reaction mixture taken in a rectangular glass pellet $(50 \mathrm{~mm} \times 50 \mathrm{~mm} \times 10 \mathrm{~mm})$ was kept at $35^{\circ} \mathrm{C}$ for a week. The prepared semi-IPNs were purified by equilibrating it in distilled water so as to ensure complete leaching of unreacted chemicals, monomer and polymers. The swelling ratio (weight of swollen gel/weight of dry gel) was found to be 4.5. The purified semi-IPNs were cut into equal sized square pieces, dried at room temperature for a week and stored in air-tight polyethylene bags.

\subsection{FTIR analysis}

The structural characterization of the semi-IPN was performed by recording IR spectra of the end-polymer on a Perkin-Elmer spectrophotometer (Paragon 1000 FTIR).

\subsection{Environmental scanning electron microscopy}

The ESEM of the prepared semi-IPNs were recorded on a scanning electron micrograph (STEREO SCAN, 430, Leica ESEM) at Indian Institute of Technology, Pawai, Mumbai (India).

\subsection{X-ray diffraction (XRD) study}

In order to ascertain the crystalline nature of the prepared semi-IPNs, the X-ray diffraction studies were carried out on Rigaku Rotating anode mode RU-H3R, X-ray powder diffractometer. The scan was taken between 3 to 70 degrees $2 \theta$ with scanning speed of $2 \% \mathrm{~min}$. The operating target voltage is $40 \mathrm{kV}$, tube current is $100 \mathrm{~mA}$ and radiation used were $\mathrm{Cu}$ alpha wavelength $1.541871 \AA$. The intensity versus $2 \theta$ scans were obtained for different samples.

The crystallinity has been measured on the premise that increasing amorphousness tends to broaden the line width whereas increasing crystallinity increases the intensity. The height $(\mathrm{CrH})$ of the main peak above its adjacent minimum represents the crystallinity of the sample and the width $(\mathrm{AmW})$ of the peak at this adjacent minimum is considered to represent the amorphousness of the sample [29]. The crystallinity CrI, is calculated from the Equation (1):

$$
\text { Percentage } \mathrm{CrI}=\left[1-t \cdot \frac{\mathrm{AmW}}{\mathrm{CrH}}\right] \cdot 100
$$

where $t$ is the scale factor relating the height of $\mathrm{CrH}$ to full scale (total blackness).

From the diffraction patterns of the various samples, the interplaner distance $\mathrm{d}$ was computed for different peaks. Bragg's equation (2) was used to determine the distance between two successive planes from which the X-rays were diffracted:

$2 d \cdot \sin \theta=n \lambda$

where $\lambda$ is the $\mathrm{X}$-ray wavelength, $\theta$ is Bragg's angle and $n$ is the order of diffraction. $d$ was calculated from the first order for various peaks obtained in the diffraction patterns (Equation (3)):

$$
d=\frac{\lambda}{2 \sin \theta}
$$

\subsection{Gamma irradiation}

The gamma irradiation of square shaped, $1 \mathrm{~mm}$ thick dry specimens were carried out at the University Science Instrumentation Centre (USIC), Nagpur University, Nagpur. Cobalt-60 Gamma Chamber-900 was used as the irradiation source. The samples were sealed and irradiated with various doses ranging from 2 to $250 \mathrm{kGy}(2,4,6,8,10$, $50,100,150,200,250)$. The average irradiation dose rate was $3.5 \mathrm{kGy} / \mathrm{h}$.

Irradiation of polymer matrix with high energy radiation may lead to scissoning of polymer chains resulting in reduction of molar mass of the polymer and consequently mechanical properties of the end polymer. Thus, the extent of degradation of polymer induced by gamma radiation was confirmed by extracting the low mol. wt. polymer with water. 


\subsection{Microhardness measurements}

The irradiated specimens were indented at room temperature by mhp-160 microhardness tester with a Vicker's diamond pyramidal indenter having a square base and $136^{\circ}$ pyramidal angle, attached to a Carl Zeiss NU2 universal research microscope [8]. The indenting load ranged from 60 to $100 \mathrm{~g}$. This was the saturation load range for the semi-IPNs at the concentration ratios under examination. The diameters of indentation were measured by a micrometer eyepiece. The Vickers microhardness, was calculated from the Equation (4):

Microhardness $=\frac{18.182178 \cdot L}{d^{2}}[\mathrm{MPa}]$

where $L$ is the load $[\mathrm{kg}]$ and $d$ is diagonal of indentation $[\mathrm{mm}]$. For each test the duration of indentation was $30 \mathrm{~s}$. For each load at least five indentations were made at different points of the specimen, and the average microhardness was computed.

\section{Results and discussion}

\subsection{Scheme of polymerization}

The whole scheme of semi IPN formation may be schematically represented as shown in Figure 1.

$$
\begin{array}{llc}
\text { a) } & \text { Redox } & R^{*} \\
\text { b) } & \mathrm{R}^{\cdot}+\mathrm{nAM} & \mathrm{R}-(\mathrm{AM})_{\mathrm{n}}- \\
& & (\mathrm{MBA}) \\
& +\mathrm{MBA} & -(\mathrm{AM})_{\mathrm{m}}- \\
& & (\mathrm{I}) \\
& & (\text { Semi-IPN) }
\end{array}
$$

Figure 1. Schematic presentation of polymerization reactions

\subsection{FTIR spectra}

The FTIR spectra of native PVA and PAM and prepared semi IPN are depicted in Figures 2a, b and c, respectively. Whereas the broadness of the spectra (Figure 2c) suggest for hydrogen bonding between the two hydrophilic polymers, the appearance of prominent bands at $3439 \mathrm{~cm}^{-1}$ (O-H stretching), $3424 \mathrm{~cm}^{-1}$ (N-H stretching) and $1698 \mathrm{~cm}^{-1}(\mathrm{C}-\mathrm{O}$ stretching) indicate the presence of hydroxyl and amide groups in the semi IPN.

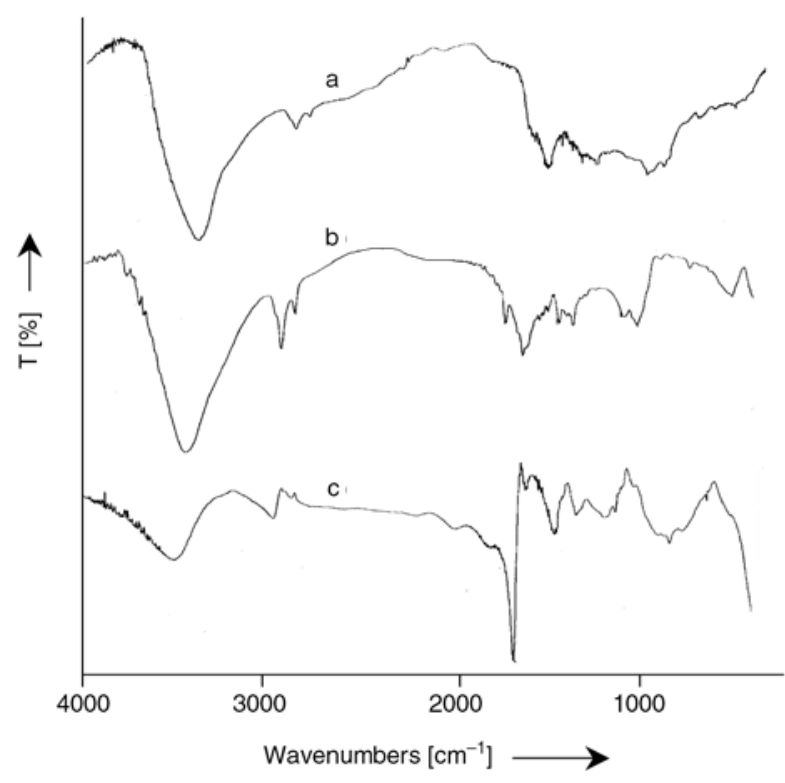

Figure 2. IR spectra of a) Native PVA, b) pure PAM and c) PVA-acrylamide semi-IPN

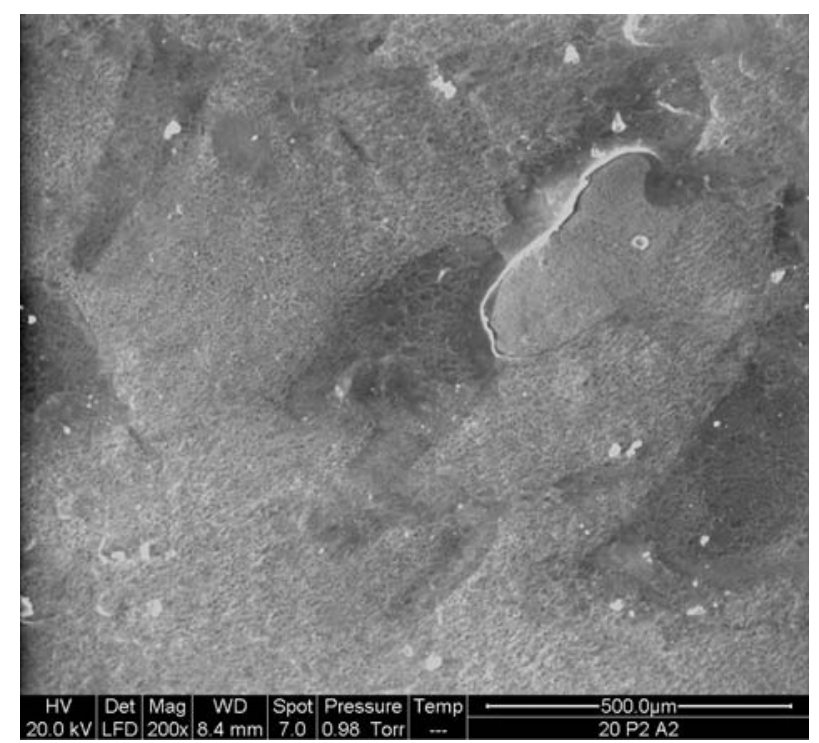

Figure 3. Environmental scanning electron micrograph (ESEM) of semi-IPN

\subsection{Morphological study}

It is clear from the ESEM image (Figure 3) that the surface of the hydrogel is heterogeneous with separated domains that suggest the phase separation during the process of IPN formation.

\subsection{XRD analysis}

The XRD patterns of native PVA (Figure 4a) shows sharp and intense peak at $17.5^{\circ}$ of $2 \theta$ and interplaner distance $5.07 \AA$. On the other hand, XRD pattern of PAM (Figure 4b) is quite broad which suggest for relatively small sized crystals of 


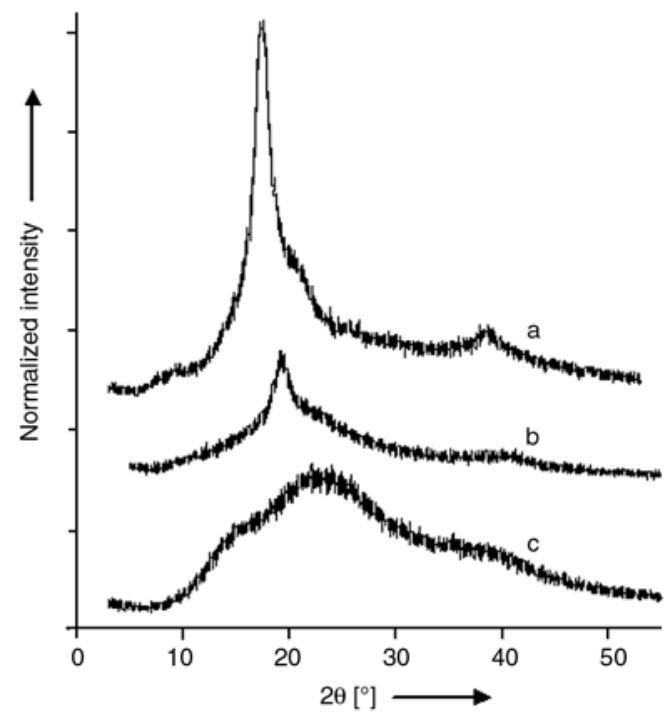

Figure 4. XRD spectra of a) native PVA, b) PVA-acrylamide semi-IPN and c) native PAM

the polymer. The XRD pattern of semi-IPN (Figure $4 \mathrm{c}$ ) indicates peak at $19.54^{\circ}$ and their semicrystalline nature (evaluated crystalinity $60 \%$ ).

\subsection{Effect of gamma irradiation on microhardness}

Figuires 5 to 8 illustrate the effect of various dose of gamma irradiation ranging from 0 to $250 \mathrm{kGy}$ respectively, on the surface microhardness of semiIPNs with varying concentration of PVA, AM crosslinker MBA, respectively.

It is evident from Figure 5 that the microhardness of irradiated PAM specimens is greater than that of the irradiated PVA specimens. In case of PAM, the value of microhardness increases at the lower dose of radiation $(2 \mathrm{kGy})$ and thereafter, it decreases with increase in dose up to $8 \mathrm{kGy}$. However, beyond this dose level, the microhardness increases

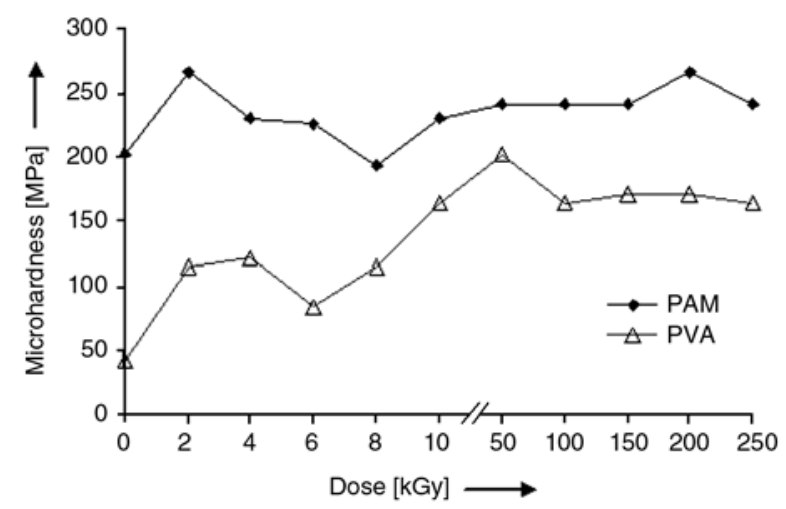

Figure 5. Variation of microhardness with various dose of gamma radiation at the load of $60 \mathrm{~g}$ for native PVA and native PAM with dose and tends to attain a maximum value at the dose of $200 \mathrm{kGy}$. Moreover, the microhardness values for all the irradiated PAM specimens are greater than the unirradiated ( 0 Gy) PAM specimens. Thus, the overall effect of gamma irradiation on PAM is that of crosslinking which leads to hardening of specimens with varying degree. The decrease in microhardness value at $8 \mathrm{kGy}$ may be due to microstructural fluctuations on the surface of the specimens. The decrease in microhardness, beyond $200 \mathrm{kGy}$, is indicative of radiation scissioning causing degradation. Likewise in case of pure PVA, as a consequence of irradiation the microhardness increases with dose up to $4 \mathrm{kGy}$ and then decreases at $6 \mathrm{kGy}$. Beyond this dose, the value of microhardness again increases up to the dose of $50 \mathrm{kGy}$ and attains a maximum value. Beyond $50 \mathrm{kGy}$, the microhardness values decrease and gets stabilized. However, the microhardness values at all the doses of radiation are higher than the unirradiated ( $0 \mathrm{~Gy}$ ) specimens. This clearly reveals that the crosslinking is predominant on exposure to gamma irradiation. The increase and decrease in microhardness may arise due to hydrophilic nature of the polymer in which the presence of moisture (water) acts as a plasticizer and may affect the experimental values in an uncontrolled way. The degree of crosslinking varies in the different dose of radiation. The increase and decrease in microhardness may also arise due to hydrophilic nature of the polymer, which acts as a plasticizer and may affect the experimental values in an uncontrolled manner. The PAM which is amorphous as confirmed from XRD studies get crosslinked to a greater extent under radiation at relatively smaller dose as revealed from microhardness measurements. The XRD results show that PVA is crys-

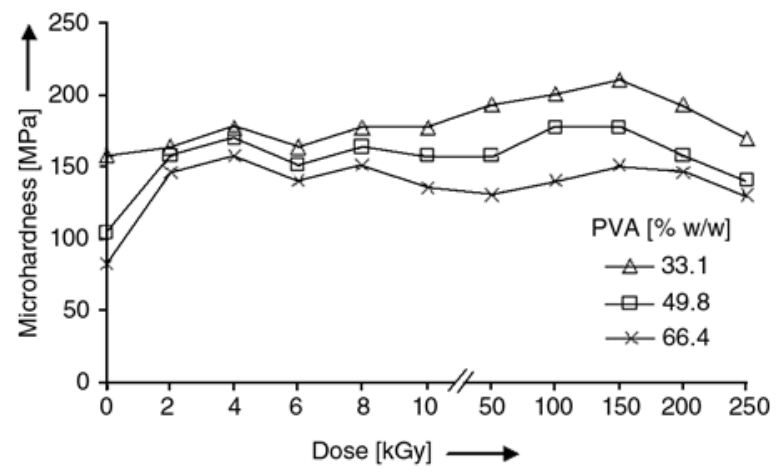

Figure 6. Variation of microhardness with varying doses of gamma radiation at the load of $60 \mathrm{~g}$ with varying content of PVA in the semi-IPN 


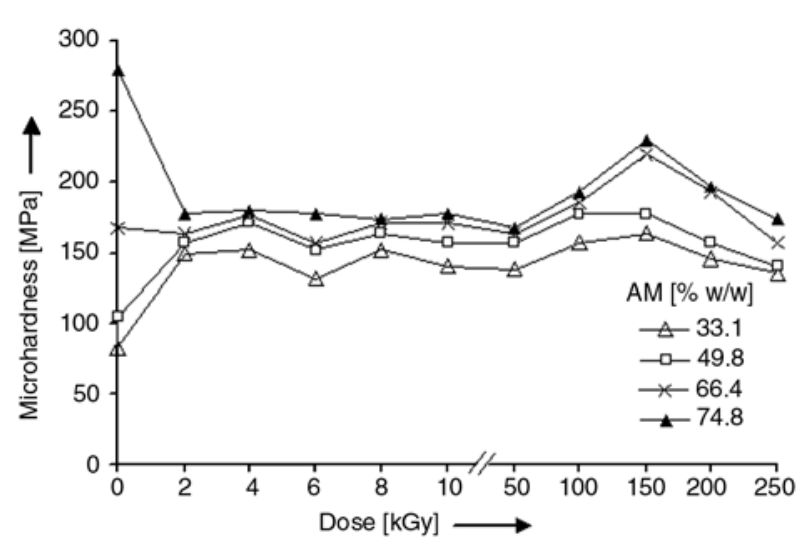

Figure 7. Variation of microhardness with varying doses of gamma radiation at the load of $60 \mathrm{~g}$ with varying content of AM in the semi-IPN

talline in nature. The irradiation of this polymer provides crosslinking at relatively wider dose range with maximum radiation crosslinking at $50 \mathrm{kGy}$.

Effect of gamma irradiation on surface microhardness of semi-IPNs having various content of PVA ranging from 33.1 to $66.4 \%(\mathrm{w} / \mathrm{w})$ is shown in Figure 6 . The figure clearly illustrates that all the irradiated specimens exhibit radiation hardening as compared to the corresponding unirradiated (0 Gy) specimens. The semi-IPN having $66.4 \%(\mathrm{w} / \mathrm{w})$ amorphous content (PAM) and $33.1 \%(\mathrm{w} / \mathrm{w})$ crystalline content (PVA), shows less effect of $\gamma$-irradiation on microhardness up to $10 \mathrm{kGy}$, and beyond which microhardness increases due to radiation crosslinking and attains the highest value at $150 \mathrm{kGy}$. At still higher dose, degradation effect is prominent indicating radiation scissioning in the specimen. On the other hand, for semi IPNs with $49.8 \%(\mathrm{w} / \mathrm{w})$ PVA content, the microhardness initially increases at the dose of $2 \mathrm{kGy}$ due to radiation crosslinking of PVA and PAM chains and, thereafter, only slight increase in hardening can be detected at the dose of 100 and $150 \mathrm{kGy}$. The varying degree of radiation crosslinking can be explained on the basis that the processes, the radiation crosslinking and scissioning occur simultaneously in crystalline and amorphous domains of the specimen. On varying the concentration of PVA, maximum irradiation effect can be observed in the specimen with $66.4 \%$ (w/w) PVA (crystalline) component. In this case, initially, microhardness increases and attains a maximum value at a lower dose of $\gamma$-irradiation, $4 \mathrm{kGy}$. Beyond this dose, the effect of irradiation on microhardness of semi-IPN lessens. The PVA acting as a plasticizer for PAM,

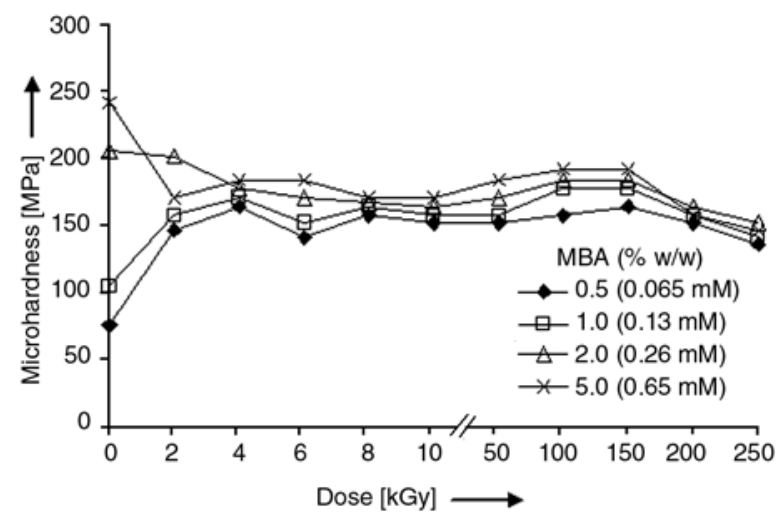

Figure 8. Variation of microhardness with varying doses of gamma radiation at the load of $60 \mathrm{~g}$ with varying content of MBA in the semi-IPN

is found to be the same even after exposure to $\gamma$-irradiation.

Figure 8 exhibits the variation of dose of gamma irradiation with microhardness for various specimens of semi-IPNs on increasing the concentration of amorphous content (acrylamide) from 1.0 to $6.0 \mathrm{~g}$ with $2.0 \mathrm{~g}$ of PVA content (semi crystalline). It is observed from the figure, that in semi-IPNs having lower acrylamide content, crosslinking is predominant in the entire irradiation dose. The microhardness values are higher as compared to the corresponding non-irradiated (0 Gy) specimen. For specimen having $33.1 \%(\mathrm{w} / \mathrm{w})$ of AM content, initially the microhardness increases at $2 \mathrm{kGy}$, thereafter, irradiation imparts less effect on microhardness and in the dose range of $50 \mathrm{kGy}$ to $200 \mathrm{kGy}$, crosslinking effect is predominant. Almost similar nature can be seen for specimen having $49.8 \%(\mathrm{w} / \mathrm{w})$ acrylamide. The profile for semi-IPN with $66.4 \%(\mathrm{w} / \mathrm{w})$ amorphous content (AM) shows very less effect of irradiation on the specimen. In this case the processes, the crosslinking and scissioning minimize the effect of each other. However, in the dose range of 100 to $200 \mathrm{kGy}$, the crosslinking is predominant and maximum value of microhardness is observed at $150 \mathrm{kGy}$. However, on increasing the non-crystallizable component (AM) to $74 \%$ in the semi-IPN, the degradation occurs in the PAM chain in the studied irradiation dose range. This effect of chain scissioning reaction is comparatively less in the range of 100 to $200 \mathrm{kGy}$ with maximum microhardness at $150 \mathrm{kGy}$, which is lower than corresponding unirradiated $(0 \mathrm{~Gy})$ specimen. These results are in correlation with the results of the studies carried by other workers [30]. They have 
reported that the glass transition temperature $\left(T_{g}\right)$ of PVA/PAM blends is observed to have increased after exposure to gamma irradiation and explained on the basis of radiation crosslinking, which introduces restrictions on the molecular motions of the chains. It has also been observed that the $T_{g}$ of PVA/PAM blends having 80\% PAM content has been decreased after exposure to $\gamma$-irradiation, this is attributed to the lower molecular polarity or lower cohesive energy density of PAM, than that for PVA. The scanning electron micrographs gave further support to the occurrence of degradation in specimen having higher content of PAM and radiation crosslinking in PVA and PVA/PAM blends with lower content of PAM upon gamma irradiation.

Figure 8 shows the variation of microhardness with various doses of radiation for semi-IPN specimens with increasing content of MBA from 0.5 to $5 \%(\mathrm{w} / \mathrm{w})$ of monomer. The figure reveals that the overall hardening is observable for the specimens having lower content of crosslinker (MBA) 0.5 to $1 \%(\mathrm{w} / \mathrm{w})$. On the other hand for higher content of MBA 2 to $5 \%(\mathrm{w} / \mathrm{w})$ surface microhardness is less than their corresponding unirradiated ( $0 \mathrm{~Gy})$ specimens. In case of lower content of crosslinker $(0.5$ and $1 \%(\mathrm{w} / \mathrm{w}))$, the value of surface microhardness initially increases at $2 \mathrm{kGy}$, and thereafter gets stabilized, and beyond the dose of $150 \mathrm{kGy}$, the degree of crosslinking decreases as the microhardness value remains higher than the value for corresponding unirradiated specimens which again supports overall hardening due to radiation crosslinking in chains of PVA and PAM. On the other hand, opposite effect on microhardness has seen, in case of higher content of crosslinker 2 to $5 \%(\mathrm{w} / \mathrm{w})$ in the semi-IPN, radiation chain scissioning reaction is predominant. For both these specimens, microhardness value remains almost constant from 4 to $10 \mathrm{kGy}$, and slight increase in microhardness can be observed in the dose range of 50 to $150 \mathrm{kGy}$. At higher dose, again the degradative effect is observable. In fact in this case, the scissioning mainly occurs in the chemically crosslinked PAM chains.

Another general but important reason for the observed variations in microhardness value of polymeric samples may be the heterogeneous nature of the specimens which may result in such microhardness variations. Moreover, the polymers used in the present work are hydrophilic in nature and as a consequence the presence of water may function as plasticizer to the polymer networks. In this way, water molecules may affect the experimental results in an uncontrolled way thus giving such variations in microhardness

\subsection{Degradation due to radiation}

In order to confirm if the prepared semi IPN suffered degradation due to exposure of radiation, the samples were subjected to extensive leaching with water and the leachate were analyzed for the polymeric constituents like PVA and polyacrylamide. The careful chemical analysis did not show any remarkable degradation. Likewise, viscometry examination also showed a marginal increase in viscosity of the water thus ruling out measurable and significant degradation of the polymer chains.

\section{Conclusions}

Redox polymerization of acrylamide in the presence of crosslinking agent (MBA) and pre-formed polymer PVA results in the formation of a semi IPN that demonstrate enhanced microhardness on exposure to gamma radiation. FTIR spectra of the un-irradiated semi IPN show the presence of functional groups of the constituent polymers and exhibit heterogeneous morphology as evident from the ESEM image.

Upon exposure to gamma radiation both the PAM and PVA show increased microhardness. In the case of the former polymer a maximum hardness is shown at $200 \mathrm{kGy}$ while the later one display the maximum hardness at $50 \mathrm{kGy}$ only.

The semi IPN exhibits a composition dependent microhardness upon irradiation. On varying the amount of PVA a maximum hardness is obtained at $33.1 \%(\mathrm{w} / \mathrm{w})$ of PVA content while the semi IPN having $74.8 \%(\mathrm{w} / \mathrm{w})$ of PAM offer maximum microhardness.

The microhardness values do not vary significantly for a given crosslinker content when exposed to gamma radiation in the range 2 to $200 \mathrm{kGy}$. However, a maximum microhardness is obtained at highest (at or more than $1 \%(\mathrm{w} / \mathrm{w}))$ crosslinker content in the semi IPN. Thus, radiation processing can be optimized with regard to the dose level and also on the percentage content of the constituent compo- 
nents of the semi-IPNs with reference to crosslinking and scissioning as desired.

\section{References}

[1] Schmedler R. H., Masters K. S., West J. L.: Photocrosslinkable polyvinyl alcohol hydrogels that can be modified with cell adhesion peptides for use in tissue engineering. Biomaterials, 23, 4325-4332 (2002).

[2] Rajvaidya S., Bajpai R., Bajpai A. K.: Morphological, thermal and annealed microhardness characterization of gelatin based interpenetrating networks of polyacrylonitrile: A hard biopolymer. Bulletin of Materials Science, 28, 529-534 (2005).

[3] Kim S. J., Yoon S. G., Kim S. I.: Synthesis and characterization of an interpenetrating polymer network composed of poly(methacrylic acid) and poly(vinyl alcohol). Polymer International, 54, 149-152 (2005).

[4] El Salmawi K. M.: Gamma radiation induced crosslinked PVA/chitosan blends for wound dressings. Journal of Macromolecular Science: Part A, 44, 541-545 (2007).

[5] Gao C., Li S., Song H., Xie L.: Radiation induced crosslinking of ultra high molecular weight polyethylene fibers by means of electron beams. Journal of Applied Polymer Science, 98, 1761-1764 (2005).

[6] Saum K. A. Sanford W. M., DiMaio W. G., Howard E. G.: Process for medical implant of cross-linked ultra high molecular weight polyethylene having improved balance of wear properties and oxidation resistance. U.S. Patent 6316158, USA (2001).

[7] Wang A., Essener A. P., Zarnowski A. J.: Process for preparing selectively cross-linked polyethylene orthopedic devices. U.S. Patent 6818171, USA (2002).

[8] Bajpai R., Dhagat N. B., Katare R., Agrawal P., Datt S. C.: Development of hardened PVF: PMMA polyblend: effect of gamma and electron irradiation. Bulletin of Materials Science, 26, 401-405 (2003).

[9] Yang J-M., Hsiue G-H.: Radiation induced graft copolymer SBS-g-VP for biomedical applications. Journal of Biomedical Materials Research, 31, 281-286 (1996).

[10] Paradossi G., Cavalieri F., Chiessi E., Ponassi V., Martorana V.: Tailoring of physical and chemical properties of macro- and microhydrogels based on telechelic PVA. Biomacromolecules, 3, 1255-1262 (2002).

[11] Gholap S. G., Jog J. P., Badiger, M. V.: Synthesis and characterization of hydrophobically modified poly (vinyl alcohol) hydrogel membrane. Polymer, 45, 5863-5873 (2004).

[12] Hassan C. M., Ward J. H., Pepass N. A.: Modeling of crystal dissolution of poly(vinyl alcohol) gels produced by freezing/thawing processes. Polymer, 41, 6729-6739 (2000).
[13] Göbbels M., Spitznas M.: Effect of artificial tears on corneal epithelial permeability in dry eyes. Graefe's Archive for Clinical and Experimental Ophthalmology, 229, 345-349 (1991).

[14] Kobayashi M., Toguchida J., Masanori O.: Development of the shields for tendon injury repair using polyvinyl alcohol- hydrogel (PVA-H) Journal of biomedical materials research, 58, 344-351 (2001).

[15] El-Salmawi K., Abu Zeid M. M., Ibraheim S. M., ElNaggar A. M., Zahran A. H.: Sorptin of dye waste by poly(vinyl alcohol)/poly(carboxymethyl cellose) blend grafted through a radiation method. Journal of Applied Polymer Science, 82, 136-142 (2001).

[16] Sayeda M. I.: Synthetic absorbent for dyestuffs based on gamma crosslinked poly (vinyl alcohol) PVA. Journal of Applied Polymer Science, 89, 349-354 (2003).

[17] Adhikari B., Majumdar S.: Polymer in sensor applications. Progress in Polymer Science, 29, 699-766 (2004).

[18] Bajpai A. K., Mishra D. D.: Absorption of a blood protein on to hydrophilic sponges based on poly(2hydroxyethyl methacrylate). Journal of Materials Science: Materials in Medicine, 15, 583-592 (2004).

[19] Stammen J. H., Williams S., Ku D. N., Guldberg R. E.: Mechanical properties of a novel PVA hydrogel in shear and unconfined compression. Biomaterials, 22, 799-806 (2001).

[20] Abd Alla S. G., Said H. M., El-Naggar A. W. M.: Structural properties of $\gamma$-irradiated poly(vinyl alcohol)/poly(ethylene glycol) polymer blends. Journal of Applied Polymer Science, 94, 167-176 (2004).

[21] Saraydin D., Karadag E., Güven O.: Relationship between the swelling process and the releases of water soluble agrochemicals from radiation crosslinked acrylamide/itaconic acid copolymers. Polymer Bulletin, 45, 287-294 (2000).

[22] Torchilin V. P.: Inmobilises enzymes as drugs. Advanced Drug Delivery Review, 1, 41-86 (1987).

[23] Lopatin V. V., Arkadskii A. A., Peregudov A. S., Vasilev V. G.: Structural and relaxation properties of medical-proposed polyacrylamide gels. Journal of Applied Polymer Science, 96, 1043-1058 (2005).

[24] Nizam El-Din H. M., Abd Alal S. G., El-Naggar A.W. M.: Radiation synthesis and characterization of hydrogels composed of poly(vinyl alcohol) and acrylamide mixtures. Journal of Macromolecular Science: Part A, 44, 47-54 (2007).

[25] Mishra S., Bajpai R., Katare R., Bajpai A. K.: Preparation characterization and microhardness study of semi interpenetrating polymer networks of polyvinly alcohol and crosslinked polyacrylamide. Journal of Materials Science: Materials in Medicine, 17, 1305-1313 (2006).

[26] Mishra S., Bajpai R., Katare R., Bajpai A.K.: Preparation and characterization of polyvinly alcohol based biomaterials: Water sorption and in-vitro blood compatibility study. Journal of Applied Polymer Science, 100, 2402-2408 (2006). 
[27] Mina M. F., Haque M. E., Balta C. F. J., Asano T., Alam M. M.: Microhardness studies of the interphase boundary in rubber-softened glassy polymer blends prepared with/without compatibilizer. Journal of Macromolecular Science: Part B, 43, 1005-1014 (2004).

[28] Bajpai A. K., Shrivastava M.: Water sorption dynamics of a binary copolymeric hydrogel of 2-hydroxyethyl methacrylate (HEMA). Journal of Biomaterials Science: Polymer Edition, 13, 237-256 (2002).
[29] Ramrakhiani M., Parashar P., Datt S. C.: Study of the degree of crystallinity in eudragit/poly(methyl methacrylate) polyblends by x-ray diffraction. Journal of Applied Polymer Science, 96, 1835-1838 (2005).

[30] El-din H. M. N., El-Naggar A. W. M., Ali F.: Miscibility of poly(vinyl alcohol)/polyacrylamide before and after gamma irradiation. Polymer International, 52, 225-234 (2003). 